\title{
Article \\ Clinical Outcomes of the Double Lateral Sliding Bridge Flap Technique with Simultaneous Connective Tissue Graft in Sextant V Recessions: Three-Year Follow-Up Study
}

\author{
Norberto Quispe-López ${ }^{1, * \mathbb{D}}$, Antonio Castaño-Séiquer ${ }^{2}$, Beatriz Pardal-Peláez ${ }^{1}$, Pablo Garrido-Martínez ${ }^{3}$, \\ Cristina Gómez-Polo ${ }^{1}$ (D) , Jesús Mena-Álvarez ${ }^{3}$ (D) and Javier Montero-Martín ${ }^{4}$ (D)
}

check for updates

Citation: Quispe-López, N.; Castaño-Séiquer, A.; Pardal-Peláez, B.; Garrido-Martínez, P.; Gómez-Polo, C.; Mena-Álvarez, J.; Montero-Martín, J. Clinical Outcomes of the Double Lateral Sliding Bridge Flap Technique with Simultaneous Connective Tissue Graft in Sextant V Recessions: Three-Year Follow-Up Study. Appl. Sci. 2022, 12, 1038. https://doi.org/ 10.3390/app12031038

Academic Editors: Ricardo Castro Alves, José João Mendes and Ana Cristina Mano Azul

Received: 24 November 2021

Accepted: 18 January 2022

Published: 20 January 2022

Publisher's Note: MDPI stays neutral with regard to jurisdictional claims in published maps and institutional affiliations.

Copyright: (C) 2022 by the authors. Licensee MDPI, Basel, Switzerland. This article is an open access article distributed under the terms and conditions of the Creative Commons Attribution (CC BY) license (https:// creativecommons.org/licenses/by/ $4.0 /)$.
1 Department of Surgery, Faculty of Medicine, Dental Clinic, University of Salamanca, 37007 Salamanca, Spain; bpardal@usal.es (B.P.-P.); crisgodent@usal.es (C.G.-P.)

2 Tenured Lecturer in Preventive Dentistry, Faculty of Dentistry, University of Seville, 41009 Sevilla, Spain; acastano@us.es

3 Department of Dentistry, Faculty of Health Sciences, Alfonso X El Sabio University, 28691 Madrid, Spain Pablogarrido86@hotmail.com (P.G.-M.); jmenaalvarez@gmail.com (J.M.-Á.)

4 Faculty of Medicine, Dental Clinic, University of Salamanca, 37007 Salamanca, Spain; javimont@usal.es

* Correspondence: norberto_quispe@usal.es

\begin{abstract}
The presence of isolated or multiple gingival recessions in the mandibular anterior region is a challenge for the clinician, as they may be associated with a shallow vestibule, high frenum insertion and/or little or no attached gingiva. Only limited evidence is available on the use of the double lateral sliding bridge flap technique with connective tissue graft (CTG) technique for treating gingival recessions in the mandibular anterior region. The aim of this study was to describe and evaluate the clinical and esthetic outcomes of the double lateral sliding bridge flap technique with CTG on isolated and multiple gingival recessions at the level of the mandibular incisors. Nine patients required treatment of gingival recessions in the mandibular incisors at the University of Salamanca (Spain) (seven females, two males; mean age: $27.9 \pm 6.9$ ) with a total of 14 isolated $(42.9 \%)$ and multiple (57.1\%) Miller class II and III gingival recessions. After a mean follow-up of 36 months, the mean percentage of root coverage was $80.5 \%$ for all treated recessions. Statistically significant differences $(p<0.05)$, were observed for reduction in recession depth, increased width of keratinized tissue and increased gingival thickness, this being dependent on the Miller class. The esthetic outcome was acceptable, with a final mean esthetic score of 7.4 out of 10 . The double lateral sliding bridge flap surgical technique with CTG is an effective procedure for the coverage of isolated and multiple gingival recessions in the anterior mandibular region, as it offers satisfactory esthetic results.
\end{abstract}

Keywords: gingival recession; connective tissue graft; root-coverage esthetic score; bridge flap technique; multiple gingival recession; localized gingival recession

\section{Introduction}

Gingival recession (GR) is defined as the apical displacement of the gingival margin in relation to the cementoenamel junction (CEJ), which exposes the root surfaces to the oral environment and is associated with attachment loss [1]. It occurs frequently in adults and increases with age [2], regardless of the level of oral hygiene [3].

It is a common clinical problem and can affect the root surface of one or several teeth, being more frequent on the vestibular surface of single-rooted teeth [1]. While in most cases gingival recessions are symptomless, the patient may see them as an esthetic problem [4] that sometimes hinders or prevents good oral hygiene and may increase the risk of root hypersensitivity [5], caries, and non-carious cervical lesions [6].

In recent decades, it has been shown that complete root coverage in single and multiple recessions can be predictably achieved with different techniques $[7,8]$. Of these procedures, 
the coronally advanced flap with connective tissue graft (CTG) is the most effective treatment of recession with or without clinical interproximal attachment loss [9-11]. Most clinical trials tend to focus on maxillary gingival recessions (esthetic zone), while little information is available on treatment of mandibular defects [12]. There are various anatomical and mucogingival conditions in the mandibular anterior region, especially sextant $\mathrm{V}$, that make treatment of an isolated or multiple GR in that region different to that performed in other sextants. Consequently, clinicians may encounter aberrant frenums with a very coronal insertion, high muscle attachment, a larger avascular surface area, malpositioned teeth that impede effective decision-making and surgical outcomes [1], shallow vestibules, and/or the presence of a thin phenotype [13]. The onset or progression of GR during or after orthodontic treatment is also more common in this region [14]. It is also important to remember that orthodontics has a vital role in managing and resolving periodontal problems [15].

In these situations, the choice of technique will depend on the characteristics of the recession and whether it is single or multiple. Several surgical techniques have been described for treating single and multiple gingival recessions in the anterior mandibular zone, including the free gingival graft technique [16], subepithelial connective tissue graft, as well as several flap designs: the envelope flap [17], coronally advanced flap [18], lateral sliding flap [19], double pedicle flap [20] and laterally closed tunnel flap [21]. For multiple gingival recessions in sextant $\mathrm{V}$, the most well-tested and predictable techniques are the bilaminar approaches such as the tunnel technique [22] and the coronally advanced flap technique [23]. However, most of these surgical techniques lead to further collapse of the vestibule, compromise the vascular supply and fail to produce predictable results in terms of complete root coverage while, in the case of the free gingival graft technique, the outcome is rather unesthetic (dissatisfaction with color matching and soft tissue texture, as well as misalignment of the mucogingival junction) [24,25].

An esthetic gingival recession scoring system (RES) has been developed to evaluate the esthetic outcome of root coverage (RC) procedures [26]. This score is based on the evaluation of five variables: the gingival margin level, gingival contour, soft tissue texture, mucogingival junction alignment, and gingival color. Sixty percent of the RES value is attributed to the level of the gingival margin, since one of the main goals of the treatment is complete root coverage (CRC), and $40 \%$ is attributed to the other four variables. The sum of the five variables produces an RES score, ranging from 0 (final recession equal or apical to the initial recession) to 10 (the best esthetic result).

Therefore, the purpose of this case series was to evaluate the efficacy of the double lateral sliding bridge flap technique with connective tissue graft in mucogingival surgery for treating isolated and multiple recessions in mandibular incisors after a mean follow-up of 36 months. The esthetic outcome was also analyzed using the RES index.

\section{Materials and Methods}

This study was approved by the Bioethics Committee of the University of Salamanca (Spain) (registration number 483, date of approval: 22 June 2020). The clinical study included nine patients (two males and seven females) with $36.0 \pm 22.1$ months of mean follow-up, who had a mean age of $27.9 \pm 6.9$, and had isolated or multiple Miller [27] class II and III gingival recessions located in the mandibular anterior region. Patients were selected from subjects who needed mucogingival surgery treatment using the double lateral sliding bridge flap technique with CTG between September 2014 and January 2020. Cases were chosen according to the following inclusion criteria. Patients were to: (1) be of legal age ( $>18$ years) and provide signed informed consent; (2) have isolated or multiple (adjacent) Miller class I, II or III recessions affecting mandibular anterior teeth; (3) have a plaque index $<20 \%$; (4) have no restorations or caries in the area to be treated; (5) have had no previous periodontal surgeries at the experimental sites; (6) have a detectable cementoenamel junction and lack of a cervical step. The following exclusion criteria were also applied, omitting: (1) smokers of more than 10 cigarettes per day; (2) patients with a systemic 
disease (diabetes, intake of drugs causing gingival enlargement, or any contraindication for mucogingival surgery).

\subsection{Surgical Protocol}

Two weeks prior to surgical treatment, dental prophylaxis and instructions on proper oral hygiene were given to the patient (Figure 1A).
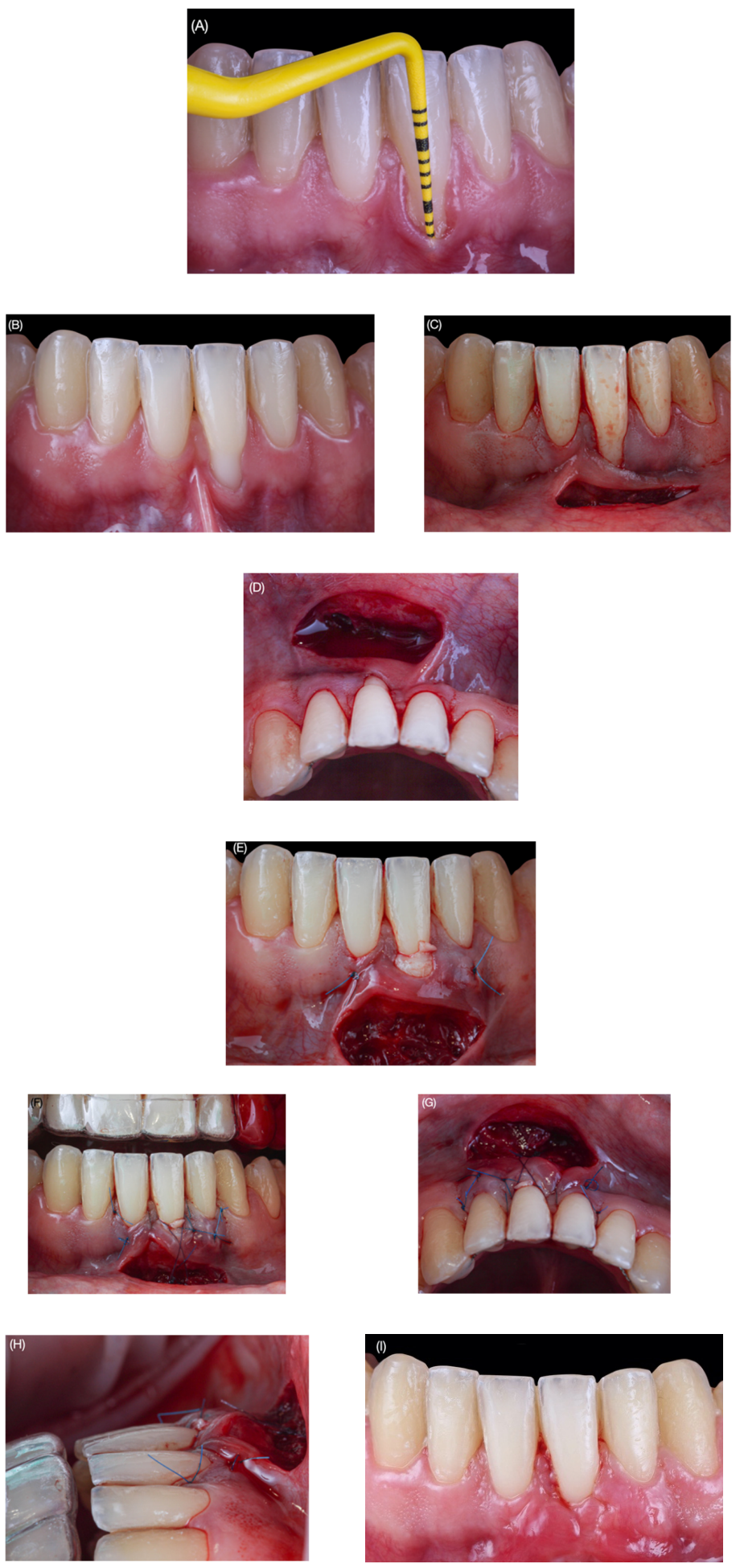

Figure 1. (A) Man with recession at the mandibular left central incisor, before the prophylaxis appointment. (B) Preoperative view, 2 weeks after prophylaxis appointment. (C) Apical horizontal 
incision at a distance $(2 \mathrm{GR}+2 \mathrm{~mm})$ from the gingival margin with recession. (D) Occlusal view. Horizontal incision made at partial thickness extending from mesial of the right central incisor to distal of the left lateral incisor. (E) Connective tissue graft sutured at the level of the CEJ using two horizontal mattress sutures. (F) Note the coronally repositioned flap and the palatal protection plate. (G) Occlusal view. Crossed horizontal mattress suture anchored in the periosteum. No suture was placed along the horizontal incision, to allow healing by second intention. (H) Lateral view. The flap, made predominantly of alveolar mucosa, was advanced coronally to completely cover the connective tissue graft. (I) After 1 month of follow-up.

All surgeries were performed by the same experienced periodontist (NQ), using the bridge flap technique with CTG. Prior to surgery, patients were required to rinse their mouths for 1 min with $0.12 \%$ chlorhexidine mouthwash $+0.05 \%$ CPC (Perio-Aid, Dentaid, Barcelona, Spain). After local anesthesia, the surgical technique began with preparation of the recipient area: a partial-thickness sulcular incision was made at the level of each recession/s using a micro-scalpel (Spoon Blade, MJK instruments, Marseille, France), dissecting apically beyond the mucogingival junction and laterally under each papilla without cutting it, extending 3 to $5 \mathrm{~mm}$ from each recession/s. Subsequently, a horizontal incision was made using a 15C scalpel blade (Swann-Morton, Sheffield, UK) in the alveolar mucosa of the bottom of the vestibule, leaving a bridge of tissue that was to serve later for a double blood supply to the CTG. The horizontal incision extended one tooth on either side of the tooth/teeth with recession/s and was made at a minimum distance of $8 \mathrm{~mm}$ from the gingival margin of the tooth with recession (Figure 1B-D).

To calculate the distance at which the horizontal incision should be made, the formula proposed by Romanos et al. [28] $(2 \times \mathrm{GR}+2 \mathrm{~mm})$ was used as a reference. The tissue coronal to the horizontal incision was subsequently repositioned apico-coronally, maintaining the marginal integrity of the tissue. The root surface was then mechanically decontaminated using Gracey curettes, treating only the exposed root surfaces with clinical attachment loss.

Once the recipient bed had been created, a CTG of $1.5 \mathrm{~mm}$ thickness was extracted from the palatal masticatory mucosa, from the upper canine to the mesial surface of the first molar. Immediate closure of the donor site was performed with horizontal mattress sutures and single stitches (Seralene ${ }^{\circledR} 5-0$, Serag-Wiessner Iberia, Madrid, Spain). Patients also received a palatal plate for protection.

The CTG was introduced through the horizontal incision and repositioned at the level of the CEJ by means of two horizontal mattress stitches using 5-0 non-absorbable suture (Seralene ${ }^{\circledR}$, Serag-Wiessner Iberia, Madrid, Spain): one located mesially and the other distally (Figure 1E).

To reposition the tissue coronally and achieve greater adaptation and stabilization of the flap and papillae, suspensory stitches were placed, including the papilla and graft, using non-absorbable 5-0 suture. Additionally, tooth-suspended sutures were placed, anchored in the periosteum, apical to the graft and suspended around the lingual side of the tooth with the recession, using 5-0 resorbable suture (SERAFAST ${ }^{\circledR}$, Serag Wiessner iberia, Madrid, Spain). The area of the horizontal incision was left to heal by secondary intention (Figure 1F-H).

A check-up was performed 1 week after the intervention and, after 15 days, we removed the sutures and observed revascularization of the graft and epithelialization of the raw area resulting from the horizontal incision. Photographic assessment and followup were performed at 1 month, 3 months and upon the final review in December 2020 (Figures 2A-C and 3A-E).

After surgery, patients received anti-inflammatory medication $(25 \mathrm{mg}$ of Dexketoprofen [Enantyum, Menarini, Barcelona, Spain] three times a day for 5 days) and antibiotics ( $1 \mathrm{~g}$ of Amoxicillin [Amoxicillin, Cinfa, Toledo, Spain] twice a day for 7 days). Patients were not allowed to brush the surgical sites for 14 days after surgery and were recommended to use a $0.12 \%+$ CPC $0.05 \%$ chlorhexidine spray (Perio-Aid, Dentaid, Barcelona, Spain) three times a day. Patients resumed tooth brushing 4 weeks after surgery, using the roll technique with a soft toothbrush. Patients were instructed not to pull on their lower lip 
and to follow a soft and liquid diet for the first days after surgery. Sutures at the donor site were removed at 7 days and sutures near the treated teeth were removed at 14 days after surgery.
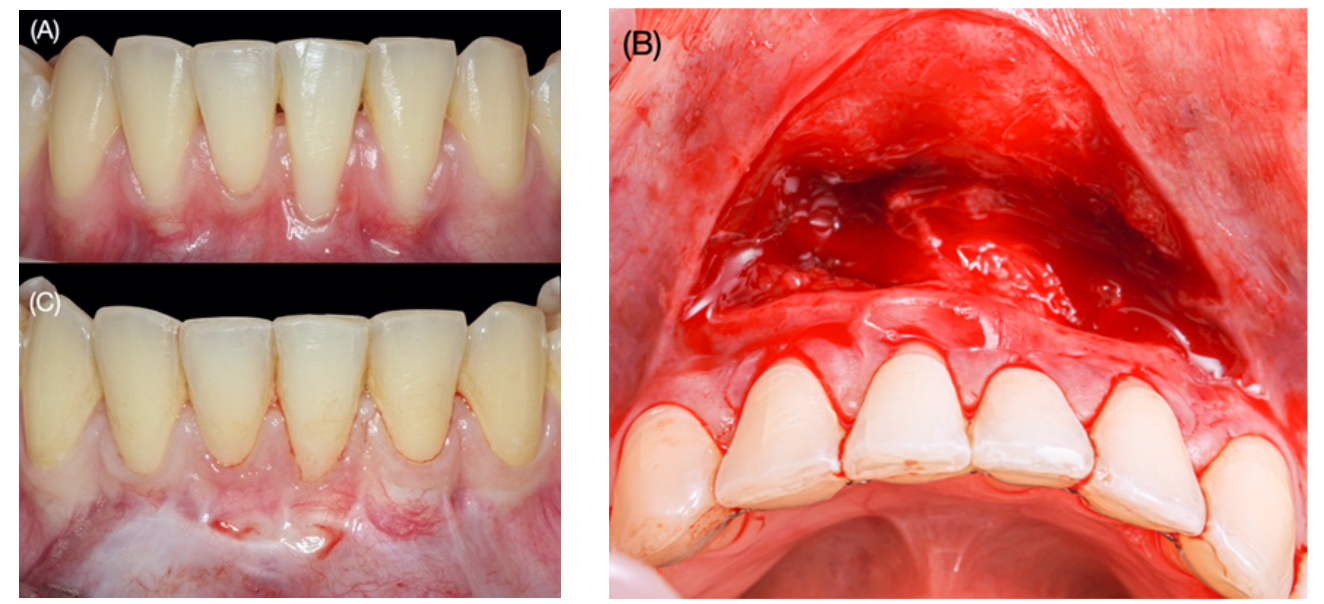

Figure 2. (A) Preoperative view, woman with multiple gingival recessions on the facial aspect from the right lateral incisor to the left lateral incisor. (B) The flap, made predominantly of alveolar mucosa, was advanced coronally to completely cover the connective tissue graft. (C) Post-treatment follow-up at 24 months. Only partial root coverage is shown on the lower left central incisor.
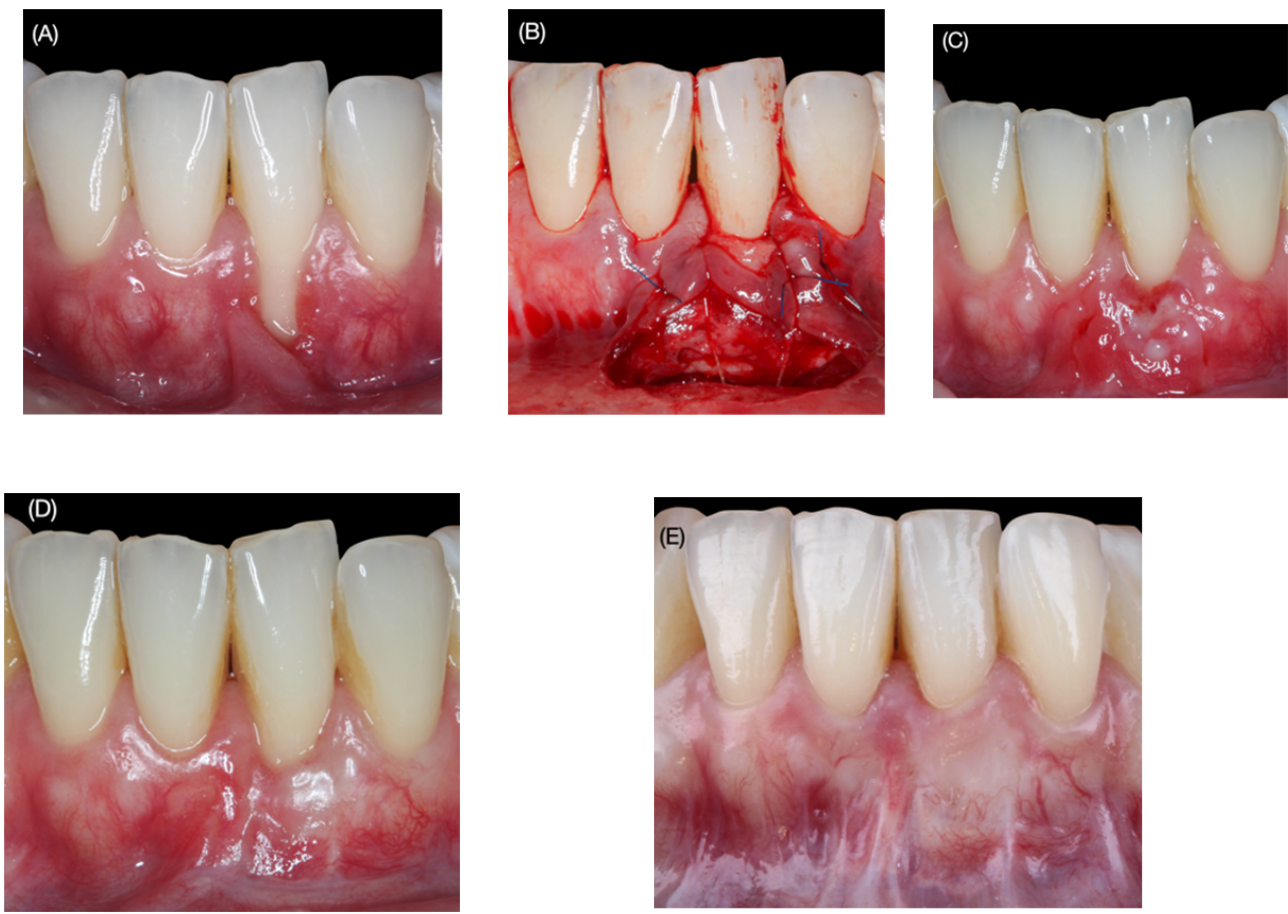

Figure 3. (A) Pre-surgery, gingival recession defect on the left central incisor. Note the narrow band of keratinized tissue and coronal frenum insertion. (B) Connective tissue graft sutured at the level of the CEJ using two horizontal mattress sutures. In this case, the graft was exposed $2 \mathrm{~mm}$. (C) Fifteen days postoperative evaluation. (D) Healing 3 months after surgery. Note the increased keratinized tissue width but the incomplete root coverage. (E) Check-up 3 years after surgery showing complete root coverage. There was spontaneous coronal migration of gingival marginal tissue, due to the phenomenon of creeping attachment. 


\subsection{Baseline Clinical Assessment}

The following clinical parameters were assessed, both at baseline and at the final postoperative evaluation, using a table corresponding to each clinical case to collect the data. All initial measurements were taken on the day of surgery using a millimetric periodontal probe by adjusting the measurement in multiples of half a millimeter (Colorvue UNC 12, Hu-friedy, Chicago, IL, USA), on the buccal midface of the teeth under study:

- $\quad$ Recession type (RT): the Miller [27] classification was used.

- Gingival recession depth (GRD), recorded in millimeters from the cementoenamel junction to the most apical point of the gingival margin.

- Probing depth (PD), recorded in millimeters from the gingival margin to the bottom of the gingival sulcus.

- Clinical attachment level (CAL): algebraic sum of the PD and GRD.

- Keratinized tissue width (KTW), measured in millimeters from the most apical point of the gingival margin to the mucogingival junction (MGJ).

- Gingival thickness (GT), measured in millimeters at $2 \mathrm{~mm}$ from the new gingival margin using a K\#10 endodontic file with rubber stop (transgingival probing) [29].

- The percentage of root coverage (RC) was calculated according to the following formula: ([preoperative REC—-postoperative REC]/preoperative REC) $\times 100$.

To evaluate the esthetic treatment outcome using the RES index, 28 photographs were taken with a Canon EOS 700D camera, Canon EF $100 \mathrm{~mm} \mathrm{f/2.8} \mathrm{L} \mathrm{Macro} \mathrm{lens} \mathrm{(Canon,}$ Tokyo, Japan) and two $60 \times 60 \mathrm{~cm}$ softboxes with studio flash (Neewer, Shenzhen, China). The patient was positioned lying on the dental chair, completely parallel to the floor, and we placed ourselves at 12 o'clock, at a distance of $0.49 \mathrm{~m}$, and with an f 20 diaphragm placing the camera lens perpendicular to the longitudinal axis of the experimental tooth. Intra-examiner reproducibility was determined by measuring PD and GRD in five different patients on two occasions, $48 \mathrm{~h}$ apart. Calibration was accepted if $90 \%$ of the recordings could be reproduced to within $1 \mathrm{~mm}$. A calibrated examiner (JM) initially examined and evaluated the images taken before and after three years of follow-up in all nine patients (intraclass correlation coefficient $=0.98 ; p<0.01$ ). This examiner (JM) was a dentist with over 20 years of experience in clinical assessments of periodontal health, although he was not familiar with the characteristics of each patient. All preoperative and postoperative images from each clinical case were imported and matched on a Keynote 2020 slide for evaluation and presentation. For each photograph, calibration was performed using parameterized digital rulers, inspired by the ABFO (American Board of Forensic Odontology) system.

\subsection{Statistical Analysis}

Variables reporting quantitative results were expressed as mean $\pm \mathrm{SD}$, median, and interquartile range. Variables reporting categorical outcomes were expressed as frequency distributions. Since most of the data did not follow a normal distribution, non-parametric tests such as the Wilcoxon signed rank test were used to evaluate differences between baseline and 36-month follow-up values for probing depth, gingival recession depth, clinical attachment level, keratinized tissue width, and gingival thickness.

Statistical analysis was performed using a statistical software program (SPSS Statistics, version 20.0, IBM). All tests were considered statistically significant when the $p$-value was $<0.05$.

\section{Results}

Nine patients with 14 isolated $(42.9 \%)$ and multiple $(57.1 \%)$ recessions in mandibular incisors were treated, of whom three (21.4\%) were classified as Miller class II and 11 (78.6\%) as Miller class III defects. Healing was uneventful in most patients. Only one patient experienced partial detachment of the connective tissue graft at 10 days. After 4 weeks, all grafts were fully integrated and completely re-epithelialized.

All clinical parameters had changed significantly between the baseline and the final examination at 36 months, as shown in Tables 1 and 2. 
Table 1. Descriptive statistics at baseline and 36-month follow-up.

\begin{tabular}{|c|c|c|c|c|c|c|c|c|c|c|c|c|c|c|}
\hline \multirow[b]{2}{*}{$\begin{array}{l}\text { Patient } \\
\text { (n) }\end{array}$} & \multirow[b]{2}{*}{ Age } & \multicolumn{8}{|c|}{ Baseline } & \multicolumn{5}{|c|}{3 Years } \\
\hline & & $\begin{array}{l}\text { Tooth } \\
\text { (FDI) }\end{array}$ & $\begin{array}{c}\mathrm{RT} \\
(\mathrm{mm})\end{array}$ & $\begin{array}{c}\text { PD } \\
(\mathrm{mm})\end{array}$ & $\begin{array}{l}\text { GRD } \\
(\mathrm{mm})\end{array}$ & $\begin{array}{l}\text { CAL } \\
(\mathrm{mm})\end{array}$ & $\begin{array}{l}\text { KTW } \\
\text { (mm) }\end{array}$ & $\begin{array}{c}\text { CEJ } \\
\text { (A/B) }\end{array}$ & $\begin{array}{c}\text { Step } \\
(+/-)\end{array}$ & $\begin{array}{c}\text { PD } \\
(\mathbf{m m})\end{array}$ & $\begin{array}{l}\text { GRD } \\
(\mathrm{mm})\end{array}$ & $\begin{array}{l}\text { CAL } \\
\text { Gain } \\
(\mathrm{mm})\end{array}$ & $\begin{array}{l}\text { KTW } \\
(\mathrm{mm})\end{array}$ & $\begin{array}{c}\mathrm{GT} \\
(\mathrm{mm})\end{array}$ \\
\hline 1 & 29 & 31 & II & 2 & 3 & 5 & 0 & A & - & 4 & 0 & 4 & 3 & 1.1 \\
\hline 2 & 27 & 41 & II & 1.5 & 2.5 & 4 & 0.5 & A & - & 2 & 0 & 2 & 3 & 1 \\
\hline 3 & 41 & 41 & III & 2 & 6 & 8 & 0.5 & A & - & 5 & 1.5 & 6.5 & 5 & 1.7 \\
\hline \multirow{2}{*}{4} & 37 & 41 & III & 2 & 1.5 & 3.5 & 4 & A & - & 2.5 & 0.5 & 3 & 4 & 1.7 \\
\hline & 37 & 31 & III & 2 & 3.5 & 5.5 & 1 & A & - & 2 & 0.5 & 2.5 & 5 & 1.2 \\
\hline 5 & 38 & 31 & III & 1 & 6 & 7 & 0 & A & - & 3 & 0 & 3 & 5 & 1.3 \\
\hline 6 & 31 & 31 & II & 2 & 4 & 6 & 1 & A & - & 2 & 0.5 & 2.5 & 3 & 1.1 \\
\hline \multirow{4}{*}{7} & 22 & 42 & III & 2 & 1.5 & 3.5 & 0 & A & - & 2 & 0 & 2 & 1 & 1 \\
\hline & 22 & 41 & III & 2 & 1 & 3 & 0.5 & A & - & 4 & 0 & 4 & 1 & 1.5 \\
\hline & 22 & 31 & III & 1 & 4 & 5 & 0 & A & - & 1.5 & 1 & 2.5 & 1 & 1.1 \\
\hline & 22 & 32 & III & 2 & 2 & 4 & 0 & A & - & 2.5 & 0 & 2.5 & 2 & 1.1 \\
\hline 8 & 28 & 31 & III & 2 & 4 & 6 & 0 & A & - & 3 & 2.5 & 5.5 & 1 & 1.5 \\
\hline \multirow{2}{*}{9} & 38 & 41 & III & 1 & 3 & 4 & 1 & A & - & 3 & 1 & 4 & 1 & 1.4 \\
\hline & 38 & 31 & III & 1 & 3 & 4 & 1 & A & - & 2 & 2 & 4 & 1.5 & 2 \\
\hline
\end{tabular}

RT: recession type; PD: probing depth; GRD: gingival recession depth; CAL: clinical attachment level KTW: keratinized tissue width; CEJ: cementoenamel junction $(\mathrm{A}=$ detectable $\mathrm{CEJ}, \mathrm{B}=$ undetectable $\mathrm{CEJ})$; STEP: + = presence of a cervical step $>0.5 \mathrm{~mm},-=$ absence of a cervical step; GT: gingival thickness.

Table 2. Clinical parameters at baseline and 36-month follow-up.

\begin{tabular}{|c|c|c|c|c|}
\hline \multicolumn{5}{|c|}{ Baseline and 36-Month Follow-Up } \\
\hline Parameters & $\mathbf{N}$ & Mean \pm SD & Range & $p$ \\
\hline GRD (mm) & 14 & & & \\
\hline Baseline & 14 & $3.2 \pm 1.5$ & $1-6$ & \\
\hline 36 months & 14 & $0.7 \pm 0.8$ & $0-2.5$ & \\
\hline Difference & 14 & $2.5 \pm 1.5$ & $1-6$ & $<0.01$ \\
\hline $\mathrm{PD}(\mathrm{mm})$ & 14 & & & \\
\hline Baseline & 14 & $1.7 \pm 0.5$ & $1-2$ & \\
\hline 36 months & 14 & $2.7 \pm 1$ & $1.5-5$ & \\
\hline Difference & 14 & $1.1 \pm 1.0$ & $0-6$ & $<0.01$ \\
\hline CAL (mm) & 14 & & & \\
\hline Baseline & 14 & $4.9 \pm 1.5$ & $3-8$ & \\
\hline 36 months & 14 & $3.4 \pm 1.3$ & $2.0-6.5$ & \\
\hline Difference & 14 & $1.5 \pm 1.4$ & $(-1)-4$ & $<0.01$ \\
\hline KTW (mm) & 14 & & & \\
\hline Baseline & 14 & $0.7 \pm 1$ & $0-4$ & \\
\hline 36 months & 14 & $2.6 \pm 1.6$ & $1-5$ & \\
\hline Difference & 14 & $1.9 \pm 1.7$ & $0-5$ & $<0.01$ \\
\hline $\mathrm{GT}(\mathrm{mm})$ & 14 & & & \\
\hline Baseline & 14 & $0.0 \pm 0.0$ & $0-0$ & \\
\hline 36 months & 14 & $1.3 \pm 0.3$ & $1-2$ & \\
\hline Difference & 14 & $1.3 \pm 0.3$ & $1-2$ & $<0.01$ \\
\hline
\end{tabular}

GRD: gingival recession depth; PD: probing depth; CAL: clinical attachment level; KTW: keratinized tissue width; GT: gingival thickness; SD: standard deviation. 
On average, the GRD was $3.2 \pm 1.5 \mathrm{~mm}$ (ranging from 1 to $6 \mathrm{~mm}$ ) at baseline, with a CAL of $4.9 \pm 1.5 \mathrm{~mm}$ (bounded in a range of 3 to $8 \mathrm{~mm}$ ). The KTW was $0.7 \pm 1 \mathrm{~mm}$ (ranging from 0 to $4 \mathrm{~mm}$ ). After surgical treatment and a 36-month follow-up, the GRD was, on average, $0.7 \pm 0.8 \mathrm{~mm}$ (range 0 to $2.5 \mathrm{~mm}$ ), representing $80.5 \% \pm 23 \%$ RC. Similarly, the CAL at the end of the evaluation period averaged $3.4 \pm 1.3 \mathrm{~mm}$ (range 2.0 to $6.5 \mathrm{~mm}$ ). The final mean KTW was $2.6 \pm 1.6$ (range 1 to $5 \mathrm{~mm}$ ), and the mean GT gain was $1.3 \pm 0.3$ (range 1 to $2 \mathrm{~mm}$ ). All of these changes were found to be statistically significant $(p<0.05)$ after a comparison with the Wilcoxon signed-rank test (non-parametric test for paired data). The non-parametric comparison of the degree of root coverage (RC) and GT gain, according to the Miller class (II and III), showed statistically significant differences $(p<0.05)$. Specifically, RC gain was significantly higher in Miller class II (95.8 $\pm 7.2 \%)$ vs. Miller class III $(76.4 \pm 24.2 \%)$. However, GT gain was significantly $(p<0.01)$ higher in Miller class III $(1.4 \pm 0.3 \mathrm{~mm})$ compared to Miller class II $(1.1 \pm 0.1 \mathrm{~mm})$.

Finally, as shown in Table 3, the change in the final esthetic outcome score averaged $7.4 \pm 2.7$ points out of 10 , with a median of 8.5 and an interquartile range of 4 . Given that all patients had scores of zero on the RES scale at the beginning of the study, these results imply that there was a $74 \%$ improvement in esthetic terms. Esthetic changes were mainly observed in the following areas: the level of the gingival margin, complete RC (undetectable CEJ) having been achieved for $64.3 \%$ of recessions; the gingival contour, an adequate marginal contour with the MGJ aligned with that of adjacent teeth having been obtained for $71.4 \%$ of recessions; and gingival color, with $78.6 \%$ of recessions having a normal color that matched the adjacent tissues. However, in $57.1 \%$ of the cases there were apical scars, compared to $42.9 \%$ in which no scars were observed.

Table 3. Detailed description of the preoperative and final recession scoring system (RES), according to Cairo et al. [26].

\begin{tabular}{lccccccccccccc}
\hline \multicolumn{10}{c}{ RES Score } \\
\hline Parameter & $\begin{array}{c}\text { Level of Gingival } \\
\text { Margin }\end{array}$ & $\begin{array}{c}\text { Marginal Tissue } \\
\text { Contour** }\end{array}$ & $\begin{array}{c}\text { Soft Tissue } \\
\text { Texture *** }\end{array}$ & $\begin{array}{c}\text { Mucogingival } \\
\text { Junction **** }\end{array}$ & $\begin{array}{c}\text { Gingival } \\
\text { Color ***** }\end{array}$ \\
\hline TF & 0 & 3 & 6 & 0 & 1 & 0 & 1 & 0 & 1 & 0 & 1 \\
\hline Score & 1 & 4 & 9 & 4 & 10 & 8 & 6 & 4 & 10 & 3 & 11 \\
\hline n. $(\%)$ & $(7.1)$ & $(28.6)$ & $(64.3)$ & $(28.6)$ & $(71.4)$ & $(57.1)$ & $(42.9)$ & $(28.6)$ & $(71.4)$ & $(21.4)$ & $(78.6)$ \\
\hline
\end{tabular}

Total Score

Average Mean

$7.4(2.7)$

(SD)

* score 0: gingival margin apical or equal to the baseline recession; score 3: partial root coverage; score 6: complete root coverage with undetectable CEJ. ${ }^{* *}$ score 0 : irregular gingival margin; score 1 : proper marginal contour. *** score 0: presence of scar formation and/or keloid-like appearance, score 1: absence of scar or keloid formation. **** score 0: mucogingival junction (MGJ) not aligned with MGJ on adjacent teeth, score 1: MGJ aligned with MGJ on adjacent teeth. ${ }^{* * * *}$ score 0 : color of tissue differs from gingival color on adjacent teeth, score 1: normal color and integration with the adjacent soft tissues. TF: mean follow-up of 36 months. Nine patients (14 sites) were evaluated at TF.

\section{Discussion}

The present study was carried out to evaluate the clinical and esthetic efficacy of treating recessions in mandibular incisors by performing the double lateral sliding bridge flap technique with CTG. This traditional technique was specifically designed to cover isolated and multiple gingival recessions at both the maxillary and mandibular levels [30]. Originally, clinicians did not use the CTG, but simply manipulated the flap by moving it coronally to achieve their root coverage goal [30]. The results obtained in the present study prove that a CTG together with the double lateral sliding bridge flap technique is a valid 
treatment option for the coverage of gingival recessions in the mandibular anterior region. Predictable techniques, such as pedicled flaps (positioned either laterally or coronally) covering the denuded root surface, with or without the use of a CTG, are available to reconstruct the soft tissues over the recession $[9,18,19]$. Systematic reviews have evaluated the efficacy of these procedures to establish root coverage percentages ranging from $35 \%$ to $97 \%$, and conclude that subepithelial connective tissue grafting (obtained from the palatal mucosa) is the surgical treatment producing the best results [31,32].

As we expected to fully correct all the recessions treated with this technique, we did not estimate the sample size at baseline, although we knew that a previous clinical trial in which this technique had been used evaluated 15 recessions in seven patients and found significant pre-post differences [33]. Currently, based on the data dispersion for gingival recession depth after 36 months of follow up $(2.5 \pm 1.5 \mathrm{~mm})$, we can estimate that the recommended sample size for this pre-post comparison is seven recessions, with a power of $80 \%$ and an alpha error of 0.05 . Since a control/placebo group may not be ethically viable, we used baseline data as controls to legitimate pre-post comparisons.

For the treatment of isolated mandibular gingival recessions, several surgical techniques have been proposed, including the use of a free gingival graft (FGG) [16] or CTG combined with various flap designs, such as the envelope flap [17], coronally advanced flap [18], laterally sliding flap [19], double pedicle flap [20], or laterally closed tunnel technique [21]. However, the scant literature we have found on the treatment of isolated and multiple recessions in sextant $\mathrm{V}$ using the bridge flap technique is limited to case series $[28,30,33]$. Furthermore, treating multiple recessions at the mandibular anterior level is more challenging, as there may be anatomical variants that affect the prognosis [1]. Graziani et al. [10] performed a systematic review and meta-analysis in which they evaluated the efficacy of the following techniques: coronally advanced flap, modified coronally advanced flap, and modified coronally advanced tunnel, in multiple recessions at both the level of the fifth sextant and the upper maxilla. Their findings suggest that the various surgical treatments are associated with moderate to high levels of clinical efficacy, obtaining more than $80 \%$ RC for Miller class I, II, and III recessions. However, none of them has become the gold standard technique. Essentially, we can currently choose between the tunnel technique and the coronally advanced flap technique with CTG $[22,23]$ to address multiple recessions in sextant $\mathrm{V}$, with few studies $[28,30,33]$ analyzing combined techniques such as that tested here. It was Marggraft [30] who proposed the double lateral bridging flap technique as a procedure for covering gingival recessions in 1985. This same technique, with certain modifications, was described by Edlan-Mejchar [34] for deepening the vestibule.

Romanos et al. [28] are among the few authors who have presented results on the double lateral bridging flap [30] technique with a follow-up of 5-8 years: in their 1993 study, complete root coverage was observed in $24 \%$ of the 75 gingival recessions treated in 18 patients. However, Romanos et al. [28] did not classify the severity of gingival recessions based on any standardized criteria (such as the Miller classification), meaning that their efficacy cannot be properly evaluated. Subsequently, Azzi et al. [35] described a modification of the Marggraft technique [30] in a clinical case in the maxilla. This variation of the technique involved adding a connective tissue graft, in addition to the incision in the bottom of the vestibule, as well as mobilizing the flap coronally to cover multiple gingival recessions and to reconstruct the papilla in Miller class IV recessions. Another analysis of this technique was published by Bethaz et al. [33] in 2014, based on findings derived from 15 recessions in seven subjects with a follow-up of up to 2 years. Both isolated and multiple recessions were treated in the mandibular anterior area, classified as Miller class I and II; bicuspids and canines were also included. This technique is similar to that used in the present study, i.e., a bilaminar technique with only one horizontal incision in the bottom of the vestibule. These researchers achieved complete $\mathrm{RC}$ in $11 / 15$ recessions $(73.3 \%)$ at 24 months; the mean RC was $90.6 \% \pm 16.8 \%$ and they obtained a mean KTW gain of $1.4 \pm 0.8 \mathrm{~mm}$. 
Compared to the outcomes achieved by Bethaz et al. [33], our results showed a slightly lower mean RC ( $80.5 \%$ vs. $90.6 \%)$, but this difference may be due to the fact that, unlike that research, the present study also included Miller class III defects in most of the treated cases. Moreover, further analysis of our data showed a mean RC of $95.8 \%$ when only Miller class II defects were included in the analysis, so our results appear to have high efficacy. Similarly, the observed KTW gain in our study was slightly higher $(1.9 \mathrm{~mm})$ than that reported in Bethaz and colleagues' research $(1.4 \mathrm{~mm})$ [33]. It should be noted that we chose to analyze the gingival thickness parameter in our study, since recent literature [1] recommends evaluating the gingival biotype, due to the higher risk of development or progression of gingival recession in cases with periodontal biotypes of $<1 \mathrm{~mm}$. Based on the above, we have observed that recessions did not recur after 36 months of follow-up, reaching a medium-term gingival stability that could be accountable to the average GT gain having been greater than $1 \mathrm{~mm}(1.3 \pm 0.3 \mathrm{~mm})$; therefore, statistically significant differences were found. Finally, in the study by Bethaz et al. [33], a fine white scar located apically in the bottom of the vestibule, which was undetectable without intraoral inspection, was also observed in $71.4 \%$ of patients, whereas in our study this occurred in $57.1 \%$ of patients (Table 3). Therefore, in just over half the cases, this surgical technique involves an esthetic limitation: the formation of a small scar that is undetectable, given its location at the bottom of the vestibule. Nevertheless, the proposed treatment is a recommendable therapeutic option for patients with a shallow vestibule, coronal frenum insertion or mandibular incisors with a lack of keratinized tissue.

Regarding the efficacy of other techniques to treat mandibular anterior recessions, it is worth highlighting the work of Aroca et al. [11], who observed complete RC in 38\% of patients ( $8 / 20$ patients) after treating Miller class III recessions with the modified tunnel technique combined with an enamel matrix derivative and CTG. While the coverage efficiency was low, the fact that their technique addressed the challenge of Miller class III recessions should be noted. Nart et al. [36] also treated a total of 14 isolated Miller class II and III recessions in mandibular incisors in 10 patients using a coronally advanced flap (CAF) and CTG. At 11.7 months after surgery, the mean RC was $90.22 \% \pm 12.36 \%$ for all recessions treated. In Miller class II defects, the mean RC was $94.04 \% \pm 10.45 \%$, while a complete RC was reached in five $(71.42 \%)$ out of seven defects. In class III recessions, the mean RC amounted to $86.41 \% \pm 13.70 \%$ and a complete RC was obtained in three out $(42.85 \%)$ of seven defects. Statistical analysis revealed no differences between the two groups. In the present study, if we limit the analysis to the results for Miller class III defects, a mean RC of $76.4 \% \pm 24.2 \%$ was obtained, which is lower than the values reported in the study by Nart and colleagues [36] (around 86\%) and higher than the results of the study by Aroca et al. [11] (around 40\%).

A recent systematic review [37] included 18 articles with 399 Miller class I and II isolated gingival recessions that were treated using the CAF technique. In this review, 43 gingival recessions affected mandibular central incisors and 26 affected mandibular lateral incisors; the mean root coverage obtained ranged from $86.28 \%$ to $91.04 \%$, and complete root coverage varied from $53.8 \%$ to $75 \%$. The high variability in the percentage of complete root coverage may be explained by the challenging anatomical conditions present in the mandibular anterior region.

The results obtained with the double lateral sliding bridge flap technique with CTG in Miller class II and III defects are promising for the treatment of isolated and multiple mandibular recessions located in the anterior region. However, it should be noted that the results are highly dependent on a careful selection of patients: in particular, whether heavy smokers are included or not [38], and the level of oral hygiene [6]. Therefore, the importance of prescribing chlorhexidine spray after the operation should be stressed, due to its bactericide and bacteriostatic properties, as well as its vital role in reducing gingival inflammation and in soft-tissue healing [39].

Recently, Parween et al. [40] performed a randomized clinical trial comparing the outcome of the modified tunnel technique with CTG with and without recombinant human 
platelet-derived growth factor (rhPDGF-BB) in 24 Miller class I and III mandibular multiple recessions. At 6 months, the mean reduction in recession depth was greater in the test group $(2.08 \pm 0.90 \mathrm{~mm})$ than in the control group $(1.83 \pm 0.93 \mathrm{~mm})$ and the mean $\mathrm{RC}$ was $82.6 \% \pm 23.69 \%$ in the test group and $56.3 \% \pm 28.55 \%$ in the control group. A mean KTW gain of 0.58 and $0.75 \mathrm{~mm}$ was observed for the control and test groups, respectively. In the present study, similar results to those of Parween [40] were observed in terms of recession depth reduction ( $2.5 \mathrm{~mm}$ vs. $2.1 \mathrm{~mm}$ in Test and $1.8 \mathrm{~mm}$ in the control). Our findings on root coverage were also comparable $(80.5 \% \pm 23 \%)$ to those observed by Parween and colleagues $(82.6 \% \pm 23.69 \%)$ in the test group. This evidence suggests that although plasma improves healing, comparable results can be obtained with the technique described here.

To analyze the esthetic results after root coverage surgery, the RES index proposed by Cairo et al. [26] was used. In our study, a mean score of 7.4 was observed, which is higher than that observed by Pini Prato et al. [41] (6.8) for the treatment of multiple maxillary and mandibular recessions. After a 6-month follow-up, Parween et al. [40] obtained a mean score of 7.6 for the control group and 8.8 for the test group in multiple mandibular recessions, which is higher than our values (Table 3). Unfortunately, we have not found any studies analyzing RES after using the double lateral sliding bridge flap technique with CTG. Therefore, it is highly recommendable for future studies to use standardized measures of esthetics to facilitate the comparison of results. In addition to the significant changes to the clinical parameters analyzed with this technique, we have been able to conclude that it is an efficient surgical procedure in mucogingival surgery in the mandibular anterior region, especially when anatomical anomalies such as aberrant frenums and shallow vestibules are present.

\section{Conclusions}

The double lateral sliding bridge flap technique with CTG appears to be a satisfactory technique for the treatment of isolated and multiple Miller class II and III recessions in the mandibular anterior region, with statistically significant gains in gingival thickness $(1.3 \pm 0.3)$, keratinized tissue width $(1.9 \pm 1.7)$ and recession depth reduction $(1.1 \pm 1.0)$. The mean percentage of root coverage was $80.5 \%$ in general and $95 \%$ in Miller type II recessions. An improvement in esthetics was also obtained, ranging from $42.9 \%$ in gingival texture to $78 \%$ in gingival color. The RES index reports good esthetic results for the double lateral sliding bridge flap technique with CTG, despite the probable appearance of scars, which are imperceptible to the patient due to their apical location.

Author Contributions: All the authors contributed to the research, supervision, writing, review, and editing of the study. Conceptualization, N.Q.-L. and J.M.-M.; methodology, N.Q.-L. and J.M.-M.; validation N.Q.-L. and J.M.-Á.; writing—original draft preparation, N.Q.-L., P.G.-M., B.P.-P.; writingreview and editing, N.Q.-L., A.C.-S., C.G.-P., J.M.-Á. and J.M.-M. All authors have read and agreed to the published version of the manuscript.

Funding: This research received no external funding.

Institutional Review Board Statement: The study was conducted according to the guidelines of the Declaration of Helsinki, and approved by the Ethics Committee of the University of Salamanca (protocol code 483, 22 June 2020).

Informed Consent Statement: Written informed consent has been obtained from the patient(s) to publish this paper.

Data Availability Statement: The datasets used and/or analyzed during the current study are available from the corresponding author on reasonable request.

Acknowledgments: The study was conducted within the Research Group "Avances en Salud Oral" (Advances in Oral Health) of the University of Salamanca. https: / / avancessaludoral.usal.es (accessed on 23 November 2021). The authors would like to thank Elena P. Hernández Rivero (SCI-Language Centre, USAL) for translation and linguistic support.

Conflicts of Interest: The authors declare no conflict of interest. 


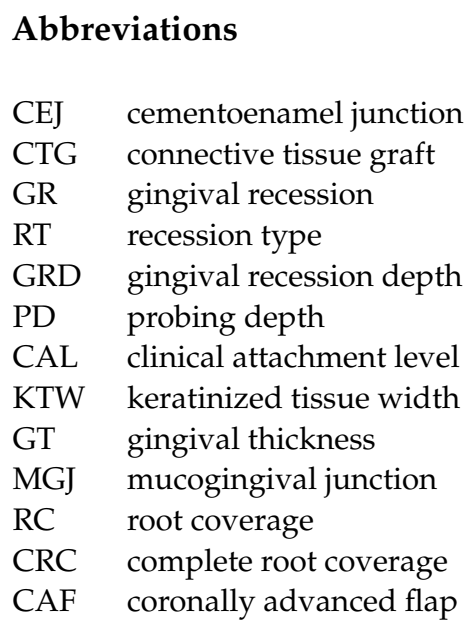

\section{References}

1. Cortellini, P.; Bissada, N.F. Mucogingival conditions in the natural dentition: Narrative review, case definitions, and diagnostic considerations. J. Periodontol. 2018, 89 (Suppl. 1), S204-S213. [CrossRef] [PubMed]

2. Hugoson, A.; Sjödin, B.; Norderyd, O. Trends over 30 years, 1973-2003, in the prevalence and severity of periodontal disease. J. Clin. Periodontol. 2008, 35, 405-414. [CrossRef]

3. Matas, F.; Sentís, J.; Mendieta, C. Ten-year longitudinal study of gingival recession in dentists. J. Clin. Periodontol. 2011, 38, 1091-1098. [CrossRef]

4. Nieri, M.; Pini Prato, G.P.; Giani, M.; Magnani, N.; Pagliaro, U.; Rotundo, R. Patient perceptions of buccal gingival recessions and requests for treatment. J. Clin. Periodontol. 2013, 40,707-712. [CrossRef]

5. Douglas de Oliveira, D.W.; Oliveira-Ferreira, F.; Flecha, O.D.; Gonçalves, P.F. Is surgical root coverage effective for the treatment of cervical dentin hypersensitivity? A systematic review. J. Periodontol. 2013, 84, 295-306. [CrossRef] [PubMed]

6. Merijohn, G.K. Management and prevention of gingival recession. Periodontol. 2000 2016, 71, 228-242. [CrossRef]

7. Cairo, F.; Pagliaro, U.; Nieri, M. Treatment of gingival recession with coronally advanced flap procedures: A systematic review. J. Clin. Periodontol. 2008, 35, 136-162. [CrossRef]

8. Cairo, F.; Nieri, M.; Pagliaro, U. Efficacy of periodontal plastic surgery procedures in the treatment of localized facial gingival recessions. A systematic review. J. Clin. Periodontol. 2014, 41 (Suppl. 15), s44-s62. [CrossRef]

9. Cairo, F.; Cortellini, P.; Tonetti, M.; Nieri, M.; Mervelt, J.; Cincinelli, S.; Pini-Prato, G. Coronally advanced flap with and without connective tissue graft for the treatment of single maxillary gingival recession with loss of inter-dental attachment. A randomized controlled clinical trial. J. Clin. Periodontol. 2012, 39, 760-768. [CrossRef]

10. Graziani, F.; Gennai, S.; Roldan, S.; Discepoli, N.; Buti, J.; Madianos, P.; Herrera, D. Efficacy of periodontal plastic procedures in the treatment of multiple gingival recessions. J. Clin. Periodontol. 2014, 41, s63-s76. [CrossRef] [PubMed]

11. Aroca, S.; Keglevich, T.; Nikolidakis, D.; Gera, I.; Nagy, K.; Azzi, R.; Etienne, D. Treatment of class III multiple gingival recessions: A randomized-clinical trial. J. Clin. Periodontol. 2010, 37, 88-97. [CrossRef]

12. Tonetti, M.S.; Jepsen, S.; Working Group 2 of the European Workshop on Periodontology. Clinical efficacy of periodontal plastic surgery procedures: Consensus report of Group 2 of the 10th European Workshop on Periodontology. J. Clin. Periodontol. 2014, 41 (Suppl. 15), S36-S43. [CrossRef] [PubMed]

13. Müller, H.P.; Könönen, E. Variance components of gingival thickness. J. Periodontal. Res. 2005, 40, 239-244. [CrossRef] [PubMed]

14. Gebistorf, M.; Mijuskovic, M.; Pandis, N.; Fudalej, P.-S.; Katsaros, C. Gingival recession in orthodontic patients 10 to 15 years posttreatment: A retrospective cohort study. Am. J. Orthod. Dentofacial. Orthop. 2018, 153, 645-655. [CrossRef] [PubMed]

15. Kaitsas, R.; Kaitsas, F.; Paolone, G.; Paolone, M.-G. Ortho-Perio Risk Assessment and timing flowchart for lingual orthodontics in an interdisciplinary adult ortho-perio patient: A case report of "Perio-Guided" Orthodontic treatment. Int. Orthod. 2021, S1761-7227, 00143-1. [CrossRef]

16. Cortellini, P.; Tonetti, M.; Prato, G.-P. The partly epithelialized free gingival graft (pe-fgg) at lower incisors. A pilot study with implications for alignment of the mucogingival junction. J. Clin. Periodontol. 2012, 39, 674-680. [CrossRef] [PubMed]

17. Nart, J.; Valles, C. Subepithelial Connective Tissue Graft in Combination with a Tunnel Technique for the Treatment of Miller Class II and III Gingival Recessions in Mandibular Incisors: Clinical and Esthetic Results. Int. J. Periodontics Restor. Dent. 2016, 36, 591-598. [CrossRef]

18. Zucchelli, G.; Marzadori, M.; Mounssif, I.; Mazzotti, C.; Stefanini, M. Coronally advanced flap + connective tissue graft techniques for the treatment of deep gingival recession in the lower incisors. A controlled randomized clinical trial. J. Clin. Periodontol. 2014, 41, 806-813. [CrossRef]

19. De Angelis, N.; Yumang, C.; Benedicenti, S. Efficacy of the lateral advanced flap in root-coverage procedures for mandibular central incisors: A 5-year clinical study. Int. J. Periodontics Restor. Dent. 2015, 35, e9-e13. [CrossRef] 
20. Harris, R.J. The connective tissue and partial thickness double pedicle graft: A predictable method of obtaining root coverage. J. Periodontol. 1992, 63, 477-486. [CrossRef] [PubMed]

21. Sculean, A.; Allen, E.-P. The Laterally Closed Tunnel for the Treatment of Deep Isolated Mandibular Recessions: Surgical Technique and a Report of 24 Cases. Int. J. Periodontics Restor. Dent. 2018, 38, 479-487. [CrossRef] [PubMed]

22. Zabalegui, I.; Sicilia, A.; Cambra, J.; Gil, J.; Sanz, M. Treatment of multiple adjacent gingival recessions with the tunnel subepithelial connective tissue graft: A clinical report. Int. J. Periodontics Restor. Dent. 1999, 19, 199-206.

23. Stefanini, M.; Zucchelli, G.; Marzadori, M.; de Sanctis, M. Coronally Advanced Flap with Site-Specific Application of Connective Tissue Graft for the Treatment of Multiple Adjacent Gingival Recessions: A 3-Year Follow-Up Case Series. Int. J. Periodontics Restor. Dent. 2018, 38, 25-33. [CrossRef] [PubMed]

24. Harris, R.J.; Miller, L.H.; Harris, C.R.; Miller, R.J. A comparison of three techniques to obtain root coverage on mandibular incisors. J. Periodontol. 2005, 76, 1758-1767. [CrossRef]

25. Kerner, S.; Sarfati, A.; Katsahian, S.; Jaumet, V.; Micheau, C.; Mora, F.; Monnet-Corti, V.; Bouchard, P. Qualitative cosmetic evaluation after root-coverage procedures. J. Periodontol. 2009, 80, 41-47. [CrossRef]

26. Cairo, F.; Nieri, M.; Cattabriga, M.; Cortellini, P.; De Paoli, S.; De Sanctis, M.; Fonzar, A.; Francetti, L.; Merli, M.; Rasperini, G.; et al. Root coverage esthetic score after treatment of gingival recession: An interrater agreement multicenter study. J. Periodontol. 2010, 81, 1752-1758. [CrossRef]

27. Miller, P.D., Jr. A classification of marginal tissue recession. Int. J. Periodontics Restor. Dent. 1985, 5, 8-13.

28. Romanos, G.E.; Bernimoulin, J.P.; Marggraf, E. The double lateral bridging flap for coverage of denuded root surface: Longitudinal study and clinical evaluation after 5 to 8 years. J. Periodontol. 1993, 64, 683-688. [CrossRef]

29. Ronay, V.; Sahrmann, P.; Bindl, A.; Attin, T.; Schmidlin, P.-R. Current status and perspectives of mucogingival soft tissue measurement methods. J. Esthet. Restor. Dent. 2011, 23, 146-156. [CrossRef]

30. Marggraf, E. A direct technique with a double lateral bridging flap for coverage of denuded root surface and gingiva extension. Clinical evaluation after 2 years. J. Clin. Periodontol. 1985, 12, 69-76. [CrossRef]

31. Chambrone, L.; Sukekava, F.; Araújo, M.-G.; Pustiglioni, F.-E.; Chambrone, L.-A.; Lima, L.-A. Root-coverage procedures for the treatment of localized recession-type defects: A Cochrane systematic review. J Periodontol. 2010, 81, 452-478. [CrossRef]

32. Tatakis, D.-N.; Chambrone, L.; Allen, E.-P.; Langer, B.; McGuire, M.-K.; Richardson, C. Periodontal soft tissue root coverage procedures: A consensus report from the AAP Regeneration Workshop. J. Periodontol. 2015, 86 (Suppl. S2), S52-S55. [CrossRef]

33. Bethaz, N.; Romano, F.; Ferrarotti, F.; Mariani, G.-M.; Aimetti, M. A mucogingival technique for the treatment of multiple recession defects in the mandibular anterior region: A case series with a 2-year follow-up. Int. J. Periodontics Restor. Dent. 2014, 34, 345-352. [CrossRef] [PubMed]

34. Edlan, A.; Mejchar, B. Plastic surgery of the vestibulum in periodontal therapy. Int. Dent. J. 1963, 13, 593-596.

35. Azzi, R.; Etienne, D.; Sauvan, J.L.; Miller, P.D. Root coverage and papilla reconstruction in Class IV recession: A case report. Int. J. Periodontics Restor. Dent. 1999, 19, 449-455.

36. Nart, J.; Valles, C.; Mareque, S.; Santos, A.; Sanz-Moliner, J.; Pascual, A. Subepithelial connective tissue graft in combination with a coronally advanced flap for the treatment of Miller Class II and III gingival recessions in mandibular incisors: A case series. Int. J. Periodontics Restor. Dent. 2012, 32, 647-654.

37. Zucchelli, G.; Tavelli, L.; Ravidà, A.; Stefanini, M.; Suárez-López Del Amo, F.; Wang, H.-L. Influence of tooth location on coronally advanced flap procedures for root coverage. J. Periodontol. 2018, 89, 1428-1441. [CrossRef]

38. Chambrone, L.; Chambrone, D.; Pustiglioni, F.-E.; Chambrone, L.-A.; Lima, L.-A. The influence of tobacco smoking on the outcomes achieved by root-coverage procedures: A systematic review. J. Am. Dent. Assoc. 2009, 140, 294-306. [CrossRef]

39. Polizzi, E.; TetÃA, G.; Bova, F.; Pantaleo, G.; Gastaldi, G.; CapparÃ, P.; Gherlone, E. Antibacterial properties and side effects of chlorhexidine-based mouthwashes. A prospective, randomized clinical study. J. Osseointegr. 2019, 12, 2-7. [CrossRef]

40. Parween, S.; George, J.-P.; Prabhuji, M. Treatment of Multiple Mandibular Gingival Recession Defects Using MCAT Technique and SCTG With and Without rhPDGF-BB: A Randomized Controlled Clinical Trial. Int. J. Periodontics Restor. Dent. 2020, 40, e43-e51. [CrossRef]

41. Pini-Prato, G.; Cairo, F.; Nieri, M.; Rotundo, R.; Franceschi, D. Esthetic evaluation of root coverage outcomes: A case series study. Int. J. Periodontics Restor. Dent. 2011, 31, 603-610. 